\title{
Relationship Between Solidification Microstructure and Hot Cracking Susceptibility for Continuous Casting of Low-Carbon and High-Strength Low-Alloyed Steels: A Phase-Field Study
}

\author{
B. BÖTTGER, M. APEL, B. SANTILLANA, and D.G. ESKIN
}

\begin{abstract}
Hot cracking is one of the major defects in continuous casting of steels, frequently limiting the productivity. To understand the factors leading to this defect, microstructure formation is simulated for a low-carbon and two high-strength low-alloyed steels. 2D simulation of the initial stage of solidification is performed in a moving slice of the slab using proprietary multiphasefield software and taking into account all elements which are expected to have a relevant effect on the mechanical properties and structure formation during solidification. To account for the correct thermodynamic and kinetic properties of the multicomponent alloy grades, the simulation software is online coupled to commercial thermodynamic and mobility databases. A moving-frame boundary condition allows traveling through the entire solidification history starting from the slab surface, and tracking the morphology changes during growth of the shell. From the simulation results, significant microstructure differences between the steel grades are quantitatively evaluated and correlated with their hot cracking behavior according to the Rappaz-Drezet-Gremaud (RDG) hot cracking criterion. The possible role of the microalloying elements in hot cracking, in particular of traces of Ti, is analyzed. With the assumption that TiN precipitates trigger coalescence of the primary dendrites, quantitative evaluation of the critical strain rates leads to a full agreement with the observed hot cracking behavior.
\end{abstract}

DOI: $10.1007 / \mathrm{s} 11661-013-1732-9$

(C) The Minerals, Metals \& Materials Society and ASM International 2013

\section{INTRODUCTION}

HoT tearing is a severe problem in many casting processes. Due to the poor mechanical properties of the mushy zone, tensile or shear mechanical stress can provoke the formation of cracks during solidification. In continuous casting, hot tearing can lead to surface and sub-surface cracking and, in the worst case, end up in a shell breakout. The breakout occurs when the shell bursts open and molten steel pours into the machine. This type of defect severely limits the productivity and causes health hazards and equipment damage.

Despite this outstanding practical relevance, there is still relatively little knowledge about hot cracking during continuous casting of steels. Several criteria have been described in the literature ${ }^{[1-5]}$ a review of all the hot tearing models can be found here. ${ }^{[4]}$ The RappazDrezet-Gremaud (RDG) criterion by Rappaz et al..$^{[1-3]}$ assumes that crack initiation occurs if the mushy zone cannot sustain the local tensile strain at a given strain rate. One of the necessary conditions is the inability to

B. BÖTTGER and M. APEL, Senior Researchers, are with the Access, Intzestr. 5, 52072 Aachen, Germany. Contact e-mail: b.boettger@access.rwth-aachen.de B. SANTILLANA, Principal Researcher, is with the Process Modelling and Casting Metallurgy Group, Steelmaking \& Casting Department, Tata Steel RD\&T, 1970 CA IJmuiden, The Netherlands. D.G. ESKIN, Professor, is with Brunel Centre for Advanced Solidification Technology (BCAST), Brunel University, Uxbridge UB8 3PH, U.K.

Manuscript submitted January 14, 2013. compensate the arising damage with the influx of the liquid phase. Consequently, the permeability and depth of the semisolid zone, determined by the morphology of the dendrites and the specific relation of the fraction liquid with temperature, should be the key parameters for the prediction of hot cracking.

Experimental measurements of permeability of real dendritic structures are very complicated and unreliable, and analytical models are used instead with various degrees of attended accuracy. Nowadays, the exact modeling of these parameters is possible using numerical simulation techniques. While cellular automaton $(\mathrm{CA})$ models ${ }^{[6,7]}$ have been frequently applied to simulation of solidification on the mesoscale, ${ }^{8]}$ phasefield models have become very popular in the field of microstructure modeling. Early model ${ }^{[9-12]}$ use only one phase-field parameter and thus are limited to the transformation between two phases or grains. As soon as more phases or grains are involved, the occurrence of triple junctions increases complexity and has been accounted for by the multiphase-field approach. ${ }^{[13-16]}$ The phase-field method has widely been applied for alloy solidification. Idealized descriptions of the phase diagrams (ideal solution approximation, ${ }^{[16]}$ linear phase diagrams ${ }^{[14]}$ ) have been used for binary and pseudobinary alloys. But, this approximation is not suitable for use in multicomponent multiphase systems. Instead, using Gibbs energy descriptions assessed from experimental data via the Calphad approach, ${ }^{[17]}$ together with software tools for Gibbs energy minimization, ${ }^{[18]}$ seems to be most promising. 
MICRESS $^{\circledR[19]}$ has been developed by Access ${ }^{[20]}$ at Aachen Technical University (RWTH). It is based on the phase-field concept for multiphase systems ${ }^{[13]}$ which has been applied to binary alloys ${ }^{[14]}$ and consequently extended to multicomponent systems ${ }^{[21,22]}$ by direct coupling to thermodynamic databases via the TQ Fortran interface to Thermo-Calc. ${ }^{[18]}$ Since then, the software has been developed further and applied to different alloy systems ${ }^{[23-27]}$ and also to steels. ${ }^{28-31]}$

This study is motivated by specific problems with hot tearing in continuous casting of industrial steel grades. Three grades, a low-carbon low-alloyed steel (LCAK) and two microalloyed high-strength steels (HSLA, LRHSLA) (Table I) showing different cracking behavior, were selected. Casting statistics ${ }^{[32]}$ indicate high risk of breakouts related to cracking for LCAK, an even slightly higher risk for the LR-HSLA grade, but substantially less hot cracking problems with the HSLA steel in the initial casting stage.

The scope of this work is to find out whether microstructure simulation can help in understanding the different hot cracking behavior of these otherwise rather similar steel grades. With this aim, phase-field modeling of solidification of the first few millimeters of the solid shell thickness, which is critical for breakouts, is performed. In the first step, only the solutal effects of the alloying elements are taken into account, and differences of the solidification microstructure and their possible effect on the cracking behavior are discussed. Afterward, precipitates which are triggered by the addition of microalloying elements are included into the simulation.

\section{PHASE-FIELD MODEL}

The multiphase-field theory describes the evolution of multiple phase-field parameters $\phi_{\alpha}(\vec{x}, t)$ in time and space. The phase-field parameters reflect the spatial distribution of different grains of different orientation and/or of a number of phases with different thermodynamic properties. At the interfaces, the phase-field variables change continuously over an interface thickness $\eta$ which can be defined as being large compared to the atomic interface thickness, but small compared to the microstructure length scale. The time evolution of the phases is calculated by a set of phase-field equations deduced by the minimization of the free energy functiona ${ }^{[15,22]}$ :

$$
\dot{\phi}_{\alpha}=\sum_{\beta} M_{\alpha \beta}(\vec{n})\left(\sigma_{\alpha \beta}^{*}(\vec{n}) K_{\alpha \beta}+\pi \eta \sqrt{\phi_{\alpha} \phi_{\beta}} \Delta G_{\alpha \beta}(\vec{c}, T)\right)
$$

$$
K_{\alpha \beta}=\phi_{\beta} \nabla^{2} \phi_{\alpha}-\phi_{\alpha} \nabla^{2} \phi_{\beta}+\frac{\pi^{2}}{\eta^{2}}\left(\phi_{\alpha}-\phi_{\beta}\right)
$$

In Eq. [1], $M_{\alpha \beta}$ is the mobility of the interface as a function of the interface orientation, described by the normal vector $\vec{n} . \sigma_{\alpha \beta}^{*}$ is the anisotropic surface stiffness and $K_{\alpha \beta}$ is related to the local curvature of the interface. The interface, on the one hand, is driven by the curvature contribution $\sigma_{\alpha \beta}^{*} K_{\alpha \beta}$ and, on the other hand, by the thermodynamic driving force $\Delta G_{\alpha \beta}$. The thermodynamic driving force, which is a function of temperature $T$ and local composition $\vec{c}=\left(c^{1}, c^{2}, \ldots, c^{k}\right)$, couples the phase-field equations to the multiphase diffusion equations for the $k$ alloying elements

$$
\dot{\vec{c}}=\nabla \sum_{\alpha=1}^{N} \phi_{\alpha} \vec{D}_{\alpha} \nabla \vec{c}_{\alpha} \quad \text { with } \vec{c} \text { defined by } \quad \vec{c}=\sum_{\alpha=1}^{N} \phi_{\alpha} \vec{c}_{\alpha}
$$

and $\vec{D}_{\alpha}$ being the multicomponent diffusion coefficient matrix for phase $\alpha . \vec{D}_{\alpha}$ is calculated online from databases for the given concentration and temperature.

The above equations are implemented in the software package MICRESS ${ }^{\circledR[19]}$ being used for the simulations throughout this paper. Direct coupling to thermodynamic and mobility databases is accomplished via the TQ-interface of Thermo-Calc Software. ${ }^{[18]}$ The thermodynamic driving force $\Delta G_{\alpha \beta}$ and the solute partitioning are calculated separately using the quasi-equilibrium approach $^{[22]}$ and are introduced into the equation for the multiple phase-fields (Eq. [1]). This allows the software package to be highly flexible with respect to thermodynamic data of a variety of alloy systems and not to be restricted by the number of elements or phases being considered. A multi-binary extrapolation scheme ${ }^{[22]}$ has been implemented in order to minimize the thermodynamic data handling, especially for complex alloy systems.

Although the phase-field code MICRESS ${ }^{\circledR}$ can be regarded as an already established software package, many improvements and optimizations had to be done in the course of this work and have been introduced into

\begin{tabular}{|c|c|c|c|c|c|c|c|}
\hline \multirow[b]{2}{*}{ Steel Grade } & \multirow[b]{2}{*}{$\mathrm{C}(\mathrm{Wt} \mathrm{pct})$} & \multirow[b]{2}{*}{$\mathrm{Mn}$ (Wt pct) } & \multirow[b]{2}{*}{$\mathrm{V}(\mathrm{Wt} \mathrm{pct})$} & \multirow[b]{2}{*}{$\mathrm{Nb}$ (Wt pct) } & \multirow[b]{2}{*}{$\mathrm{Ti}$ (Wt pct) } & \multicolumn{2}{|c|}{$\mathrm{N}(\mathrm{ppm})$} \\
\hline & & & & & & Aim & Max \\
\hline LCAK & 0.045 & 0.22 & - & - & - & - & 50 \\
\hline LR-HSLA & 0.045 & 0.8 & 0.04 & 0.013 & $<0.01$ & 80 & 100 \\
\hline HSLA & 0.045 & 0.8 & 0.13 & 0.013 & $<0.01$ & 130 & 150 \\
\hline
\end{tabular}
the code, especially with respect to the integrated 1D

Table I. Typical Chemical Composition of Three Steel Grades 
temperature solver (see below) and to an effective postprocessing of the simulation results (e.g., evaluation of the fraction solid-temperature relation).

\section{SIMULATION SETUP}

During the initial formation of a solid shell at the mold region, the local temperature field in the solidifying region is highly transient and non-linear. To obtain a realistic temperature boundary condition for phase-field simulation of continuous casting, a one-dimensional temperature solver is integrated. According to the high diffusivity of heat $\lambda$ compared to solutes, a much lower spatial resolution is required for the temperature field. As the temperature diffusion length exceeds the typical interdendritic distance, the temperature field is expected to be mostly one-dimensional under these conditions, and a 2D temperature solver is not required.

The low resolution allows the temperature field to reach deeply into the casting, ideally down to the center of the casting, without causing too much computational effort (Figure 1). By means of this, the temperature $T$ can be explicitly solved in the 1D field including a boundary condition at both sides, while latent heat from the simulation domain is released averaged from the zone which corresponds to one grid cell in the lowresolution temperature field ${ }^{[33]}$.

$$
\dot{T}=\frac{1}{\bar{C}_{\mathrm{p}}}\left(\nabla \sum_{\alpha} f_{\alpha} \lambda_{\alpha} \nabla T+\sum_{\alpha} H_{\alpha} \dot{f}_{\alpha}\right),
$$

where $f_{\alpha}$ is the average fraction of phase $\alpha, \bar{C}_{\mathrm{p}}$ is the average heat capacity, and $H_{\alpha}$ is the enthalpy per phase in each temperature grid cell. As bottom boundary condition of the $1 \mathrm{D}$ temperature field, the time-dependent slab surface temperature (Figure 2) was used, obtained by a calibrated numerical process model of the industrial continuous caster. ${ }^{[34]}$

During most of the simulation time, the complete solidification interval, and thus the major part of the

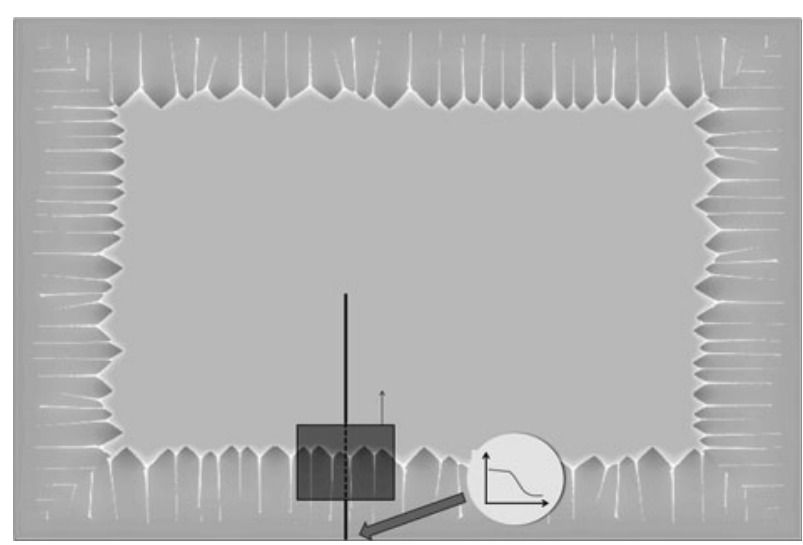

Fig. 1-Schematic representation of the position of the simulation domain (small rectangular region) and the external $1 \mathrm{D}$ temperature field (black line) in the cross section of the strand. latent heat release, is located inside the simulation domain (darker rectangular zone in Figure 1). To insure a correct calculation of latent heat outside this domain, an iterative "homoenthalpic" approach was used. In this approximation, a uniform $H(T)$ relation in the region where temperature is solved is assumed. In this way, it is possible to find a macroscopic temperature solution which is consistent with the microscopic latent heat release. ${ }^{[33]}$

The boundary conditions for the concentration fields and the phase boundaries (phase-field parameter field) which are chosen at the different sides of the simulation domain are of utmost importance if the simulation domain is not huge. Periodic conditions on the left and right boundary of the simulation domain turned out not to be the best choice when selection of columnar dendrites with spontaneous nucleation of equiaxed grains is simulated. They easily lead to the dominance of one dendrite orientation, even if it is not well aligned to the temperature gradient. The reason for this behavior is that periodic boundary conditions allow dendrites to interact through the boundary which effectively decreases their average distances. A twice as big simulation domain would be needed to compensate for this effect. To avoid that, isolated boundary conditions were used on the right and left side of the simulation domain. For the top concentration boundary, a fixed condition was used to assure that the far-field concentration remains constant (and equal to the average alloy composition). At the bottom, an isolation (Neumann) boundary condition was used.

The microscopic simulation domain was 2000 grid cells high and had a width of 1000 to 5000 cells; the grid cell size $\Delta x$ was $0.333 \mu \mathrm{m}$. An interface thickness $\eta$ of $1 \mu \mathrm{m}$ was chosen. For the one-dimensional macroscopic temperature field, 3000 grid cells with a grid cell size of $15 \mu \mathrm{m}$ were chosen. As thermal conductivity, a constant value of $35 \mathrm{Wm}^{-1} \mathrm{~K}^{-1}$ has been chosen for the melt and temperature-dependent values for fcc identical to those of pure iron. ${ }^{[35]}$

As the simulation domain did not include the whole length of the solidification process, the solidification

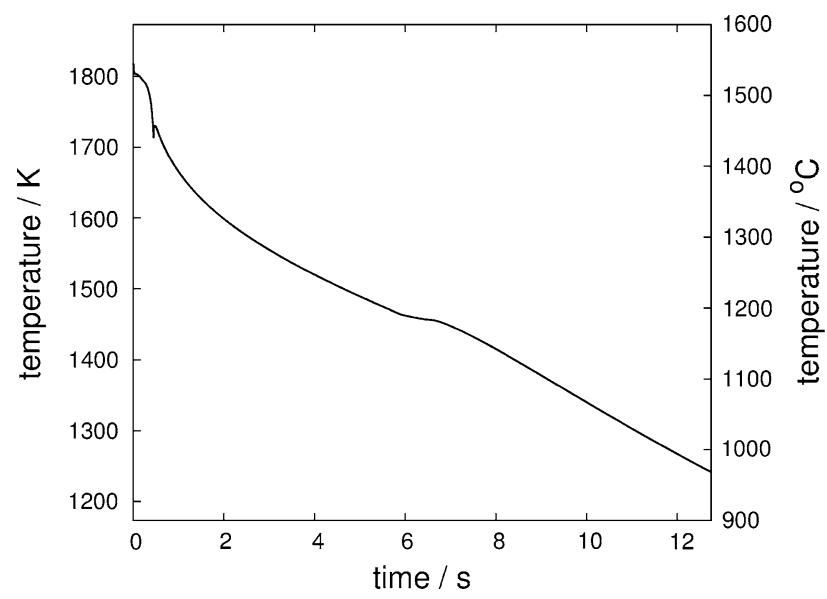

Fig. 2-Slab surface temperature which was used as thermal boundary condition for the bottom of the temperature field. 
front was tracked by using a moving-frame boundary condition. The tracking criterion was a constant distance of the highest dendrite tip from the top of the simulation domain.

Interface mobility values for the liquid $/ \delta$-ferrite interface have been calibrated (see Section IV); for all other interfaces, they were estimated. Numerical parameters of the interfaces are given in Table II.

Thermodynamic data were obtained directly by coupling to the thermodynamic database TCFE6. Diffusion coefficients for the solid phases were taken from the mobility database MOB2; ${ }^{18]}$ for the liquid phase, they were estimated to $1 \times 10^{-5} \mathrm{~cm}^{2} \mathrm{~s}^{-1}$ for all elements.

\section{CALIBRATION OF INTERFACE KINETICS}

It is well known that phase-field models suffer from numerical artifacts if spatial resolution is not sufficiently high. ${ }^{[36,37]}$ If the interface thickness is not much smaller than the diffusion length of all elements, the interface kinetics deviate from the sharp interface solution due to "artificial solute trapping." As an additional problem, the interface may even get unstable if the driving force varies too much over the length of the diffuse interface. For the case of solidification, there have been attempts to correct for these artifacts by introducing an antitrapping current to the diffusion equations and by applying a suitable correction to the interface mobility (the so-called "thin interface limit"). ${ }^{[38,39]}$ Those approaches are often referred to as "quantitative" phasefield models. But, even when rigorous thin interface corrections are considered, the interface thickness has to be in the order of the capillary length, and the required grid would still be too fine for practical application of the phase-field method to multicomponent and multiphase technical alloys.

Therefore, in this work, another approach has been used in order to obtain quantitative interface kinetics: An averaging of the driving force $\Delta G$ along the normal vector of the interface was performed in order to reduce "artificial solute trapping" and to stabilize the interface profile. Furthermore, a small interface thickness $(\eta=3 \Delta x=1 \mu \mathrm{m})$ was used which further helps reducing trapping artifacts. Artifacts originating from the small number of interface grid points were minimized by using a correction scheme for numerical discretization errors. ${ }^{[40]}$

Interface kinetics which correspond to the sharp interface limit have finally been achieved by calibration of the interface mobility for such a coarse grid $(\Delta x=0.333 \mu \mathrm{m})$ by means of reference simulations of the same system with high resolution $(\Delta x=0.05 \mu \mathrm{m})$. The reference simulation had a small domain size $(400 \times 2000$ grid cells) and was performed for only one dendrite at the initial stage of solidification where the cooling rate is high and the diffusion length in the melt is small. The simulation was repeated increasing the mobility of the liquid- $\delta$-ferrite interface stepwise, until (above $\mu \sim 1.0 \mathrm{~cm}^{4} \mathrm{~J}^{-1} \mathrm{~s}^{-1}$ ) the growth velocity of the dendrite tip did not increase anymore. This indicates that diffusion-limited growth was reached and that the grid resolution was sufficiently high. The results then were taken as reference results.

Afterward, the simulation was repeated for the same domain size, but using the lower grid resolution of $\Delta x=0.333 \mu \mathrm{m}$. By systematic variation of the interface mobility of the liquid- $\delta$-ferrite interface, a calibrated value was obtained which reproduces not only the correct diffusion-limited interface kinetics but also the shape of the dendrite with its individual side branches, as defined by the high-resolution reference simulation. Values of $0.065 \mathrm{~cm}^{4} \mathrm{~J}^{-1} \mathrm{~s}^{-1}$ and $0.054 \mathrm{~cm}^{4} \mathrm{~J}^{-1} \mathrm{~s}^{-1}$ were found for LCAK and the two HSLA grades, respectively.

\section{NUCLEATION}

Nucleation is not intrinsically included in phase-field models. One of the main problems when explicitly including nucleation into a phase-field model is that small particles are only stable if they are bigger than the interface thickness $\eta$. Therefore, a "small grain" approach has been implemented which stabilizes smaller particles and provides them with a correct analytical curvature. ${ }^{[25]}$ When the particle is growing, the "small grain" approach is continuously changed to the normal phase-field model.

As a criterion for nucleation, the driving force (or undercooling) for the new phase is calculated according to the quasi-equilibrium (parallel tangent) approach, ${ }^{[22]}$ which is done by explicit access to the thermodynamic database.

A model for heterogeneous nucleation of the primary phase from the melt was integrated because nucleation can affect grain selection in columnar growth. This model is inspired by a statistical approach to heterogeneous nucleation in equiaxed solidification ${ }^{[41-43]}$ which is based on the assumption of a density

Table II. Numerical Interface Parameters

\begin{tabular}{|c|c|c|c|c|c|}
\hline \multirow[b]{2}{*}{ Interface } & \multirow{2}{*}{$\begin{array}{c}\text { Interface Energy } \\
\quad\left(\mathrm{J} \mathrm{cm}^{-2}\right)\end{array}$} & \multirow{2}{*}{$\begin{array}{l}\text { Static Anisotropy } \\
\text { Coefficient }\end{array}$} & \multicolumn{2}{|c|}{$\begin{array}{l}\text { Interface Mobility } \\
\qquad\left(\mathrm{cm}^{4} \mathrm{~J}^{-1} \mathrm{~s}^{-1}\right)\end{array}$} & \multirow{2}{*}{$\begin{array}{c}\text { Kinetic Anisotropy } \\
\text { Coefficient }\end{array}$} \\
\hline & & & LCAK & HSLA & \\
\hline Liquid- $\delta$-Ferrite & $2.5 \times 10^{-5}$ & 0.3 & 0.065 & 0.054 & 0.05 \\
\hline Liquid-TiN & $1.0 \times 10^{-4}$ & - & $1.0 \times 10^{-6}$ & $1.0 \times 10^{-6}$ & - \\
\hline$\delta$-Ferrite-TiN & $1.0 \times 10^{-4}$ & - & $1.0 \times 10^{-12}$ & $1.0 \times 10^{-12}$ & - \\
\hline
\end{tabular}


distribution of heterogeneous nuclei with different diameters $d$. The critical undercooling for nucleation then is

$$
\Delta T_{\mathrm{Nuc}}=\frac{4 \sigma}{\Delta S d}
$$

where $\Delta S$ is the entropy of fusion and $\sigma$ the solid-liquid interfacial energy. This basic idea has been extended to a fully spatially resolved model which further accounts for inhomogeneous composition ${ }^{[25]}$ and temperature ${ }^{[33]}$ distributions. At the beginning of each simulation run, the potential nucleation sites are randomly distributed over the domain, according to the given seed density distribution, and attributed with the critical nucleation undercooling given by the nucleant size according to Eq. [5]. If this critical undercooling is reached locally, a grain with random orientation is set.

The seed density distribution $d N / d r$ is defined by an arbitrary number of seed classes which have a different radius $r$ and such a different critical nucleation undercooling. Unfortunately, nothing is known about seeds in the melt during continuous casting of the alloy grades studied in this paper. Therefore, in this work, a simple three-parameter log-normal distribution function was used (where $N$ is the total number density of potential seed particles, $r_{0}$ the average radius, and $s$ describes the broadness of the distribution):

$$
\begin{gathered}
\frac{\mathrm{d} N}{\mathrm{~d} r}=\frac{N}{s r \sqrt{2 \pi}} \exp \left(\frac{1}{2}\left[\frac{\ln (r)-\mu}{s}\right]^{2}\right) \\
\mu=\ln \left(r_{0}\right)-\frac{s^{2}}{2}
\end{gathered}
$$

A set of parameters $\left(r_{0}=0.05, s=0.14\right.$ and $N=2 \times 10^{6}$ ) has been chosen so as to match experimental observations ${ }^{[44]}$ and is used in this paper for all alloy grades.

3D orientation distributions of the new seeds have to be taken into account to assure that the probability of a new grain either to block the front (eventually leading to equiaxed structures) or to form a new columnar grain is correct. To obtain that also in $2 \mathrm{D}$ simulations, the misorientation in $3 \mathrm{D}$ is transformed into a misorientation in 2D, i.e., angular deviations of the growth direction from the temperature gradient direction are projected into the $2 \mathrm{D}$ simulation plane.

Carbonitride particles (TiN, Section X) are assumed to precipitate at the ferrite-liquid interface at low temperatures shortly before the end of solidification. Because no corresponding experimental data on nucleation under such conditions have been found in the literature, a value of $5^{\circ} \mathrm{K}$ was chosen for the local critical undercooling. Below this value, a seed is formed. Checking for TiN nucleation was performed at the whole liquid- $\delta$-ferrite interface at intervals of $1 \times 10^{-2} \mathrm{~s}$.

\section{RDG CRITERION FOR CRACK INITIATION}

Hot tears are gaps and cracks which might form during casting, when the temperatures of sub-areas of the material are between (non-equilibrium) solidus $\left(T_{\mathrm{s}}\right)$ and liquidus $\left(T_{1}\right)$ and are subject to simultaneously acting tensile stresses. ${ }^{[3]}$ Hot tears typically initiate above the (non-equilibrium) solidus temperature at volume fractions of the solid phase above 0.85 to 0.9 and propagate mainly through the interdendritic liquid film. One of the conditions for hot tearing is the lack of liquid feeding of the mushy zone, especially at the end of solidification and, more precisely, when grains start to impinge and finally touch one another, but are still largely separated by a continuous liquid film. ${ }^{[3]}$

A strain rate-based criterion was developed by Rappaz et $a l^{[1]}$ and adapted for steels by Drezet et al. ${ }^{[2]}$ The model is based on a mass balance for the liquid and solid phases and allows for calculating the pressure drop contributions in the mushy zone. It assumes a tensile deformation perpendicular to the growth direction of the dendrites and describes the induced interdendritic liquid feeding flow. If this flow cannot compensate for thermal contraction (thermal strain) and for solidification shrinkage at a given strain rate, a void may form and initiate a crack. This is assumed to happen when the pressure in the interdendritic liquid falls below a critical pressure $p_{\mathrm{c}}$,

$$
p_{\mathrm{c}}=p_{\mathrm{a}}+p_{\mathrm{m}}-\Delta p_{\mathrm{sh}}-\Delta p_{\varepsilon}
$$

where $p_{\mathrm{a}}$ is the atmospheric pressure, $p_{\mathrm{m}}$ is the ferrostatic pressure, and $\Delta p_{\mathrm{sh}}$ and $\Delta p_{\varepsilon}$ are the pressure drop contributions in the mushy zone associated with solidification shrinkage and thermal contraction (deformation), respectively. The maximum strain rate $\dot{\varepsilon}_{\text {crit }}$ which can be sustained by the mushy zone can be calculated by integration of the total pressure drop over the mushy zone $\mathrm{e}^{[1]}$ :

$$
\begin{aligned}
\dot{\varepsilon}_{\text {crit }} & =\frac{G}{(1+\beta) B}\left[\frac{\lambda_{2}^{2} G \Delta p_{\max }}{180 \mu}-v_{\mathrm{T}} \beta A\right] \\
\text { with } A & =\int_{T_{\mathrm{c}}}^{T_{1}} \frac{\left(1-f_{\mathrm{s}}\right) f_{\mathrm{s}}^{2}}{\left(1-f_{\mathrm{s}}\right)^{3}} \mathrm{~d} T \text { and } B=\int_{T_{\mathrm{c}}}^{T_{1}} \frac{f_{\mathrm{s}}^{2}\left(\int_{T_{\mathrm{c}}}^{T} f_{\mathrm{s}} \mathrm{d} T\right)}{\left(1-f_{\mathrm{s}}\right)^{3}} \mathrm{~d} T
\end{aligned}
$$

where $\mu$ is the dynamic viscosity of the liquid phase, $G$ is the thermal gradient, $v_{\mathrm{T}}$ is the velocity of the isotherms, $\beta$ is the solidification shrinkage factor, $A$ and $B$ are integrals over the temperature interval between the coalescence $T_{\mathrm{c}}$ and the liquidus temperature $T_{\mathrm{l}}$, and $f_{\mathrm{s}}$ is the fraction of solid. $G, v_{\mathrm{T}}, A, B$, and $\lambda_{2}$ are obtained from the phase-field simulation results.

At the coalescence temperature $T_{\mathrm{c}}$, the thin liquid film between dendrites is interrupted and a solid connection is formed, which corresponds to the onset of ductility. According to the RDG criterion, below $T_{\mathrm{c}}$, no initiation of hot cracks is possible anymore. This is why $T_{\mathrm{c}}$ is believed to have a crucial impact on hot cracking. 
There is little knowledge about the coalescence process itself and how it is affected by alloy chemistry, morphology, and precipitates. But, from experimental evidence in other materials, $T_{\mathrm{c}}$ could been estimated to be the temperature which corresponds to a solid fraction of 0.99 in the case of grain boundaries and of 0.95 inside a grain. ${ }^{[3]}$ In this work, the value of 0.99 was adopted as the default value. In simulations where the effect of $\mathrm{Ti}$ was taken into account, $T_{\mathrm{c}}$ was modified if nucleation of TiN occurred. As the eutectic phase, TiN locally also promotes further growth of the $\delta$-ferrite dendrites. Keeping in mind the extremely small width of the liquid film between the dendrites, we assume TiN nucleation should trigger coalescence. Therefore, the temperature of interdendritic TiN precipitation was used for $T_{\mathrm{c}}$ if it was above the temperature corresponding to $f_{\mathrm{s}}=0.99$.

Taking into account the vulnerable time $t_{\mathrm{v}}$ proposed by Clyne and Davies, ${ }^{[5]}$ a critical strain during this time interval can be defined as follows:

$$
\varepsilon_{\text {crit }}=\dot{\varepsilon}_{\text {crit }} \cdot t_{\mathrm{v}}
$$

where $t_{\mathrm{v}}$ is the time period during which the mushy zone is between $T_{\mathrm{c}}$ and $T_{90}$. Here, the subscript 90 means 90 pct of the solid phase. This interval is increasing with the solidification length due to changing solidification parameters.

\section{SIMULATION RESULTS}

For the low-alloyed steel grade (LCAK), only three elements ( $\mathrm{Fe}, \mathrm{Mn}, \mathrm{C})$ have been taken into account (Table I). Figure 3 shows a time series of results for the carbon concentration distribution in LCAK which demonstrates how morphology formation is proceeding. The solid-liquid interface and its development are clearly visible over the time range between 0.2 seconds and 3.0 seconds. The first seeds grow from the melt and form equiaxed grains (a-b). Due to the strong temperature gradient and dendrite selection, the solidification front rapidly assumes a columnar structure (c-d). At this stage (d), the thickness of the mushy zone reaches a minimal value (distance between dendrite tips and the lowest points where liquid phase still exists), which is due to the extremely strong cooling rate (see Figure 2) leading to a strong thermal gradient at this stage. Later (e-f), gradient and cooling rate are decreasing, which leads to a coarsening of the microstructure. Nucleation of equiaxed grains ahead of the front is scarce. The choice of the nucleation parameter is responsible for that, which is in accordance with experimental findings. ${ }^{\text {[4] }}$

For the LR-HSLA and HSLA steel grades, the microalloying elements $\mathrm{Nb}, \mathrm{V}$, and $\mathrm{N}$ have been taken into account (Table I). This makes simulation considerably more time- and memory consuming and had the consequence that for these grades, simulations could not be finished completely (until the slab leaves the caster, see, e.g., Figures 7 and 12). But, this is not crucial for the validity of the results and was needed to find out whether and how these elements are affecting micro- structure and, thus, the hot cracking behavior. Ti was still neglected at this stage, because no content was defined in the alloy specification, and the typical concentration is very low $(-0.003 \mathrm{wt}$ pct $)$. Figure 4 shows the concentration distribution of all five alloying elements for HSLA after 0.4 seconds' solidification time, according to a phase-field simulation. All considered elements show a positive segregation, i.e., they enrich the interdendritic region during solidification. In the completely solidified region at the bottom of the simulation domain, $\mathrm{C}$ and $\mathrm{N}$ reach a rather smooth distribution, which is due to their high solid state diffusivity. The other slow diffusing elements (Mn, V, and $\mathrm{Nb}$ ) retain their segregation pattern.

The positive validation of the simulation results with shell thickness measurements ${ }^{[45]}$ and experimentally obtained microstructure quantities has been presented and discussed in a previous publication. ${ }^{[4]}$

\section{QUANTITATIVE EVALUATION OF SIMULATED MICROSTRUCTURE}

The microstructure differences between LR-HSLA and HSLA are by far smaller than those between LCAK and HSLA. This is reasonable if we compare the compositions of the steel grades given in Table I. Apart from the lack of microalloying elements, the Mn content of LCAK is almost 4 times lower compared to the other two grades.

The quantitative evaluation includes the determination of the secondary dendrite spacing $\lambda_{2}$ which is an important input parameter for the RDG criterion (Eq. [9]). This evaluation has been done for different positions along the solidification path. In Figure 5, a $\log -\log$ plot of $\lambda_{2}$ vs the local solidification time (measured between $f_{\mathrm{L}}=1$ and $f_{\mathrm{L}}=0.01$ ) is shown. The coefficients for the empirical exponential relation $\lambda_{2}=a \Delta t^{b}$ are given in Table III. For all three steel grades, the exponent $b$ is close to the theoretic value of 0.333 , while the constants, $a$, are slightly different. Consequently, the secondary dendrite spacing $\lambda_{2}$ shows the highest values for LCAK and the smallest for HSLA, which is in agreement with the increasing alloy concentration.

Furthermore, the fraction liquid-temperature curves are very important for the hot cracking susceptibility. The simulation results for the three alloy grades are compared in Figure 6 (top). They were obtained by integrating the simulation results for various time steps over all averaged isothermal rows of grid cells and a subsequent smoothing using a cubic spline function. For better comparison, a reference region was chosen between $\mathrm{x}=1.0$ and $2.0 \mathrm{~mm}$, over which averaged fraction liquid-temperature curves were obtained. This region was also selected for further evaluations which are described in the following part.

By shifting the resulting fraction liquid-temperature curves for HSLA and LR-HSLA, they could be aligned at a fraction liquid of $f_{\mathrm{L}}=0.1$ (Figure 6 , bottom). This relative shifting allows for a better comparison of the shapes of the curves and the length of the vulnerable 

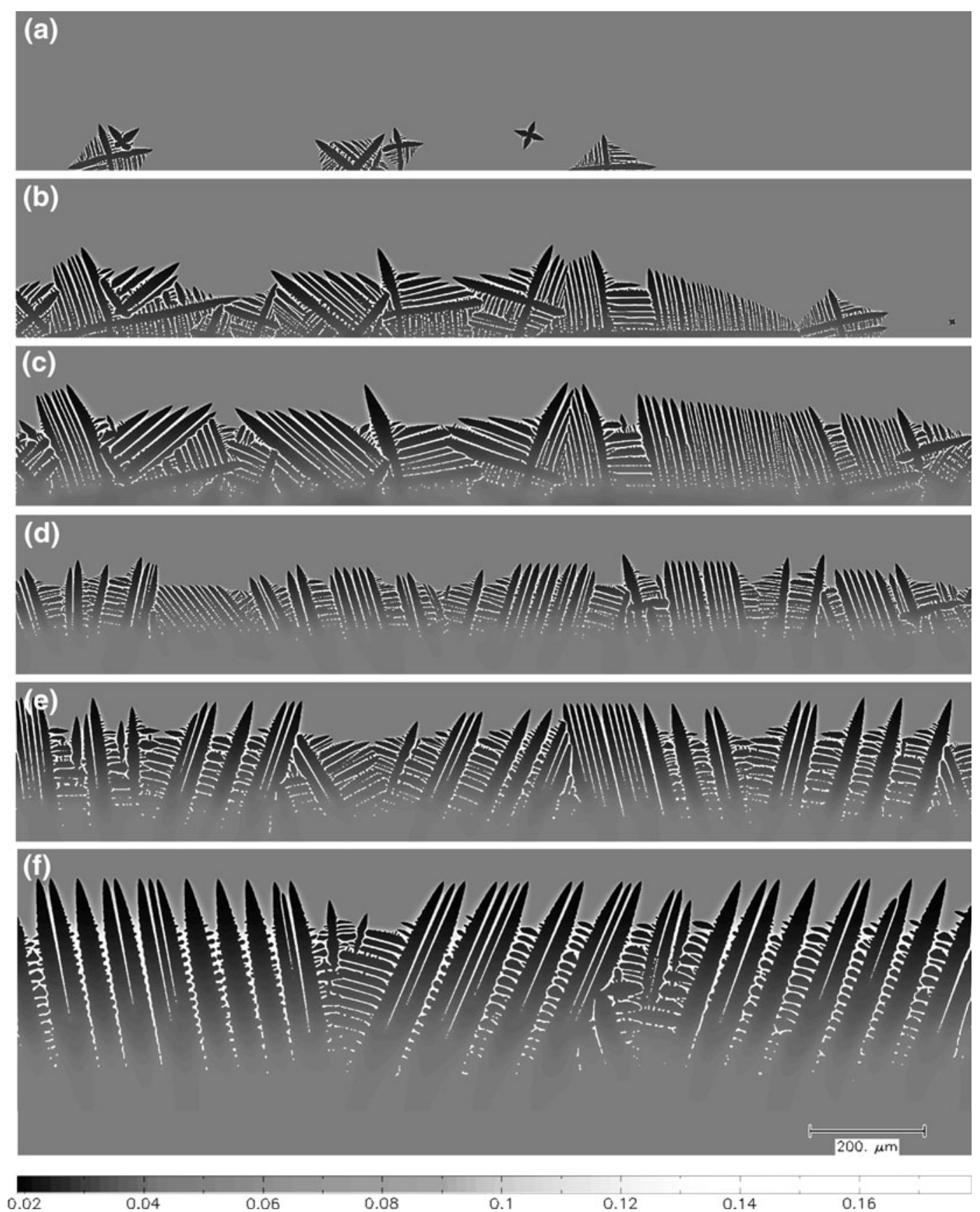

Fig. 3-Time sequence for solidification of LCAK. The C distribution is shown after $(a) 0.20 \mathrm{~s},(b) 0.25 \mathrm{~s},(c) 0.30 \mathrm{~s},(d) 0.50 \mathrm{~s},(e) 1.0 \mathrm{~s},(f) 3.0 \mathrm{~s}$.

temperature range between $f_{\mathrm{L}}=0.1$ and $f_{\mathrm{L}}=0.01$, which is important for hot cracking (see Section IX). The results are as follows: While LCAK shows the steepest $f_{\mathrm{S}} / T$ curve and thus the smallest solidification temperature interval, HSLA and LR-HSLA exhibit an increased thickness of the semisolid region, which is due to the higher concentrations of the alloying elements $\mathrm{Mn}, \mathrm{Nb}, \mathrm{V}$, and $\mathrm{N}$. The difference between the two HSLA grades (which is only caused by the different content of $\mathrm{V}$ and $\mathrm{N}$ ) is smaller, but still significant. The obtained temperatures for $f_{\mathrm{L}}=1, f_{\mathrm{L}}=0.1$, and
$f_{\mathrm{L}}=0.01$ as well as the vulnerable temperature interval $\Delta T\left(f_{\mathrm{L}}=0.01\right.$ to 0.1$)$ are summarized in Table III.

Further quantitative microstructure parameters obtained by phase-field simulations have been presented elsewhere. ${ }^{[4]}$

In summary, significant differences in microstructure have been found, even between HSLA and LR-HSLA, which are consistent with the different amounts of alloying elements. The consequences for hot cracking, according to the RDG criterion, ${ }^{[1-3]}$ are evaluated in the following section. 

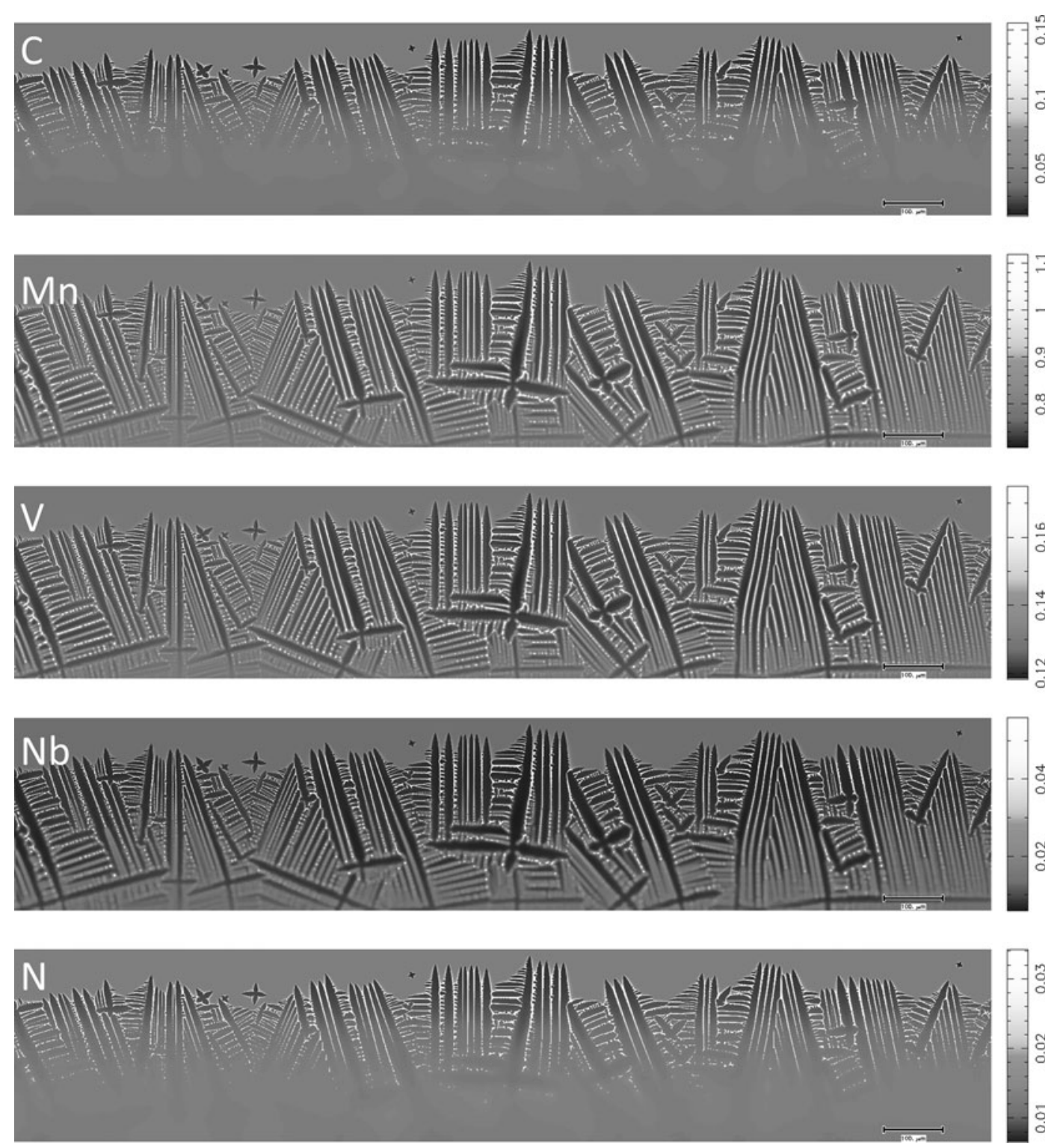

Fig. 4 Concentration distribution of all elements in wt pet for HSLA at $t=0.4 \mathrm{~s}$.

\section{EVALUATION OF THE HOT CRACKING SUSCEPTIBILITY USING THE RDG CRITERION}

The RDG criterion for hot cracking is applied according to Eq. [9]. The fraction solid curve $f_{\mathrm{S}}(T)$, the temperature gradient $G$, the velocity of the isotherms $v_{\mathrm{T}}$ (both at $f_{\mathrm{S}}=0.99$ ), and the vulnerable time $t_{\mathrm{v}}$ (Eq. [10]) are evaluated and averaged for different intervals of the solidification length as given in Table III. $\Delta p_{\max }$ is taken to be the standard atmospheric pressure plus the ferrostatic pressure which corresponds to the height of the melt at solidification time. The solidification shrinkage factor $\beta$ and the dynamic viscosity $\mu$ are 0.057 and $0.00645 \mathrm{~Pa} \mathrm{~s}$, respectively.

Figure 7 shows the critical strain rates according to Eq. [9] for different solidification lengths. A low value of $\dot{\varepsilon}_{\text {crit }}$ is equivalent to the prediction of a high risk of hot cracking. Very close to the slab surface $(x=0.25 \mathrm{~mm})$, $\dot{\varepsilon}_{\text {crit }}$ is very small, indicating an increased cracking risk. The negative values for HSLA and LR-HSLA even imply cracking (or porosity formation) without strain. But, at this early stage of casting and solidification, cracking susceptibility should not be critical as cracks can be easily healed by penetrating melt.

For higher depths inside the slab, corresponding to a later stage of solidification, the critical strain rate $\dot{\varepsilon}_{\text {crit }}$ shows nearly constant values. If the resulting hot cracking risk is compared with the observed frequencies of breakouts observed during production, an agreement with respect to LCAK and LR-HSLA is found: Obviously, the higher concentration of $\mathrm{Mn}$, but also of $\mathrm{V}$, $\mathrm{Nb}$, and $\mathrm{N}$, leads to a stronger segregation in LRHSLA, a deeper mushy zone, and thus to an increased risk of cracking. According to this analysis, HSLA should show an even slightly higher risk of breakouts compared to LR-HSLA. But, as was pointed out in 
Section I, HSLA shows a strongly reduced breakout risk, which cannot be understood on the basis of this purely solutal analysis.

The critical strain rate $\dot{\varepsilon}_{\text {crit }}$ and critical strain $\varepsilon_{\text {crit }}$ for the reference location $x=1$ to $2 \mathrm{~mm}$ are given in Table IV.

\section{PRECIPITATION OF CARBONITRIDE PARTICLES}

As has been shown in Section IX, the low cracking risk of HSLA cannot be explained only from the solutal effects of the elements $\mathrm{V}$ and $\mathrm{N}$ which have been added in comparison to LR-HSLA. The main purpose of the addition of these elements is the formation of $\mathrm{VN}$ at lower temperatures, which enables ferrite grain refinement in thermo-mechanically controlled processing (TMCP). But, the high solubility of VN (and also of $\mathrm{Nb}(\mathrm{C}, \mathrm{N})$ ) excludes the possibility that precipitation takes place at higher temperatures which are relevant for hot tearing.

$\mathrm{Ti}$ is the only microalloying element which is known to form nitrides at rather high temperatures. Although it is not explicitly specified as an alloying element in the steel grades considered in this paper, this element is present with a typical content of 0.002 to 0.004 pct. If its precipitation as TiN or co-precipitation with other microalloying elements as $(\mathrm{Ti}, \mathrm{V}, \mathrm{Nb})(\mathrm{C}, \mathrm{N})^{[46]}$ can

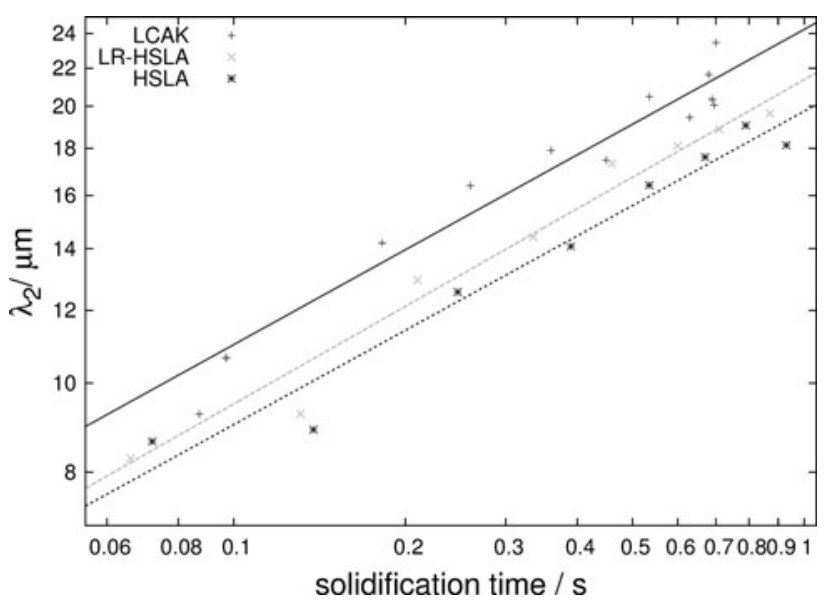

Fig. 5-Dependency of $\lambda_{2}$ with local solidification time for LCAK, HSLA, and LR-HSLA. The data can be represented by the following exponential relation $\lambda_{2}=a \Delta t^{b}$ (coefficients $a$ and $b$ as given in Table III) happen before solidification is finished, an influence of Ti on hot cracking is possible, and the higher $\mathrm{V}$ and $\mathrm{N}$ content of HSLA could perhaps explain the altered breakout risk of this alloy!

In the following part, the precipitation tendency for carbonitrides was simulated for LR-HSLA and HSLA. An additional small content of 0.003 pet $\mathrm{Ti}$ was assumed. It must be pointed out that on the scale of the dendrites, carbonitride particles cannot be properly resolved due to the much too coarse grid. Each

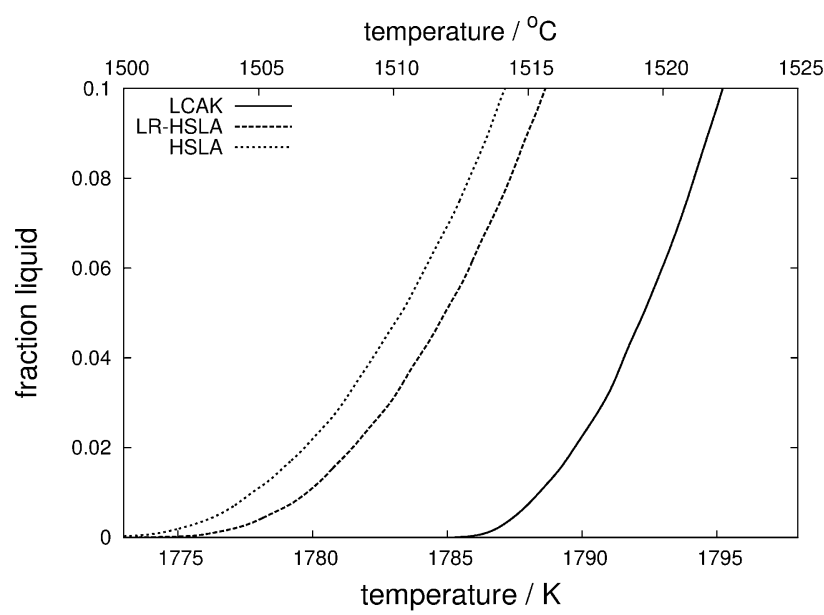

(a)

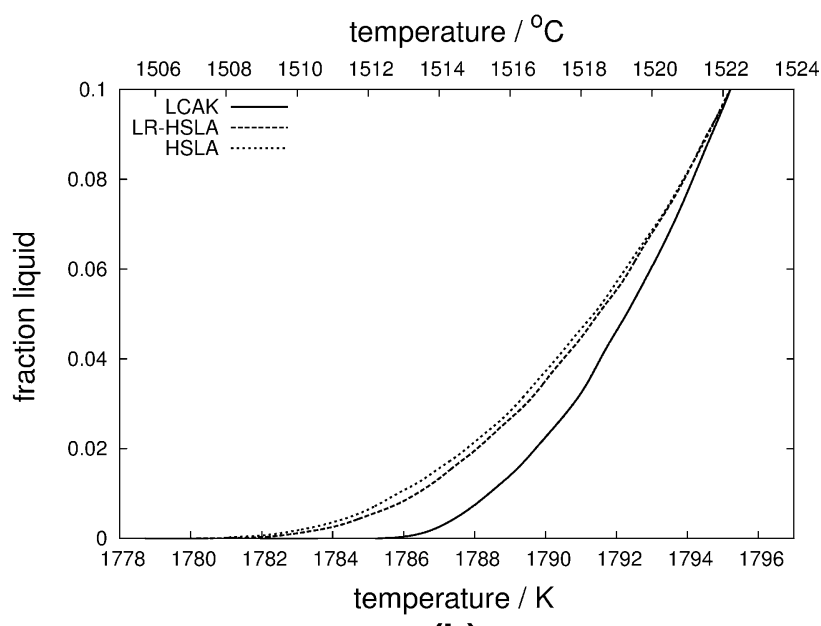

(b)

Fig. 6-Top-Comparison of the fraction liquid-temperature curves for LCAK, HSLA, and LR-HSLA for the $x=1.0$ to $2.0 \mathrm{~mm}$. Bottom-For better comparison, the curves have been aligned at the temperature where $f_{\mathrm{L}}=0.1$.

Table III. Averaged Microstructure Parameters for the Reference Position (1 to $2 \mathrm{~mm}$ )

\begin{tabular}{lcccccc}
\hline & & & & \multicolumn{2}{c}{$\begin{array}{c}\lambda_{2}=a \Delta t^{b} \\
(\mu \mathrm{m})\end{array}$} \\
\cline { 3 - 7 } & & & & & & \\
Steel Grade & $T_{1}\left[\mathrm{~K}\left({ }^{\circ} \mathrm{C}\right)\right]$ & $T\left(f_{\mathrm{L}}=0.1\right)\left[\mathrm{K}\left({ }^{\circ} \mathrm{C}\right)\right]$ & $T\left(f_{\mathrm{L}}=0.01\right)\left[\mathrm{K}\left({ }^{\circ} \mathrm{C}\right)\right]$ & $\Delta T\left(f_{\mathrm{L}}=0.01\right.$ to 0.1$)$ & $a$ \\
\hline LCAK & $1801.47(1528.32)$ & $1795.55(1522.40)$ & $1788.52(1515.37)$ & 7.03 & 24.25 & 0.3429 \\
LR-HSLA & $1796.86(1523.71)$ & $1788.32(1515.17)$ & $1779.57(1506.42)$ & 8.75 & 21.38 & 0.3528 \\
HSLA & $1796.78(1523.63)$ & $1787.37(1514.22)$ & $1777.89(1504.74)$ & 9.48 & 19.76 & 0.3409 \\
\hline
\end{tabular}




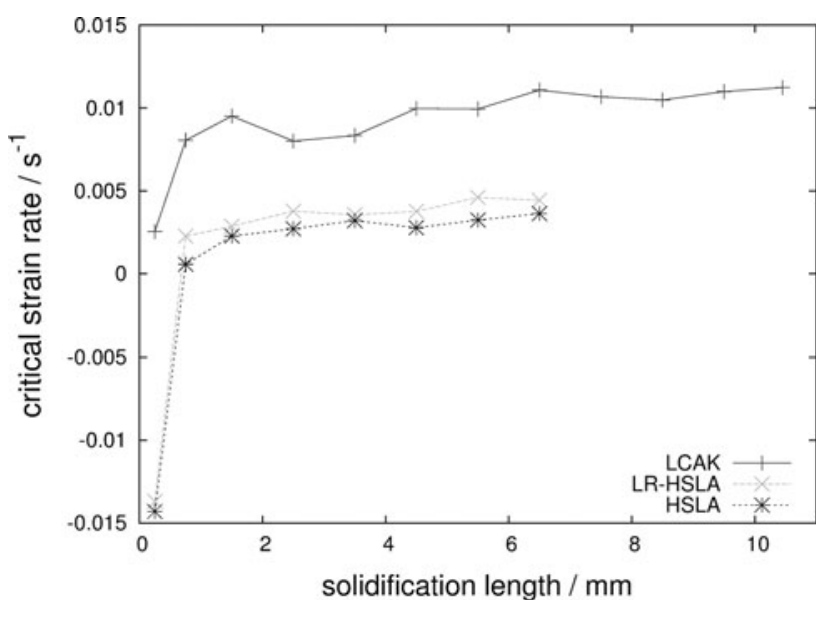

Fig. 7-Critical strain rate according to the RDG criterion, as function of the solidification length.

Table IV. Critical Strain Rate $\dot{\varepsilon}_{\text {crit }}$ and Critical Strain $\varepsilon_{\text {crit }}$ for the Reference Position (1 to $2 \mathrm{~mm}$ ) and for Different Steel Grades (Without Ti)

\begin{tabular}{lcc}
\hline Steel Grade & $\dot{\varepsilon}_{\text {crit }}\left(\right.$ Pct s $\left.^{-1}\right)$ & $\varepsilon_{\text {crit }}($ Pct $)$ \\
\hline LCAK & 0.9514 & 0.06660 \\
LR-HSLA & 0.2855 & 0.02513 \\
HSLA & 0.2273 & 0.02205 \\
\hline
\end{tabular}

precipitate is typically represented by a single grid cell with a fraction of the carbonitride phase $<1$, and curvature is calculated using the assumption that this particle forms a sphere. In view of these restrictions, no morphological information apart from the integral particle size can be expected from the simulations. Also, the particle size and density are not representative because nothing is known about nucleation data and no experimental data were available for calibration. For this reason, the evaluation presented here is focusing only on the temperature when carbonitrides are formed and on their phase fraction.

In order to find out whether carbonitride particles could affect the hot cracking behavior of the selected steel grades, the first question to be addressed is at which temperature and at which sites precipitation of this phase can occur. For this purpose, a simulation setup with a rather small simulation domain of $300 \times 2000$ grid cells and a resolution of $0.333 \mu \mathrm{m}$ was chosen. No moving frame was applied in this case because the focus was also on precipitation of carbonitrides in ferrite and austenite at lower temperatures. Figure 8 shows the amount of carbonitrides for HSLA and LR-HSLA in a temperature range between $1523 \mathrm{~K}$ and $1793 \mathrm{~K}$ $\left(1250^{\circ} \mathrm{C}\right.$ and $\left.1520^{\circ} \mathrm{C}\right)$. Particles which were nucleated from the melt, the $\delta$-ferrite, and the $\gamma$-austenite were distinguished and evaluated separately.

According to the simulation results, most of the total amount of carbonitrides forms either in the melt at temperatures above about $1723 \mathrm{~K}\left(1450{ }^{\circ} \mathrm{C}\right)$ or from the

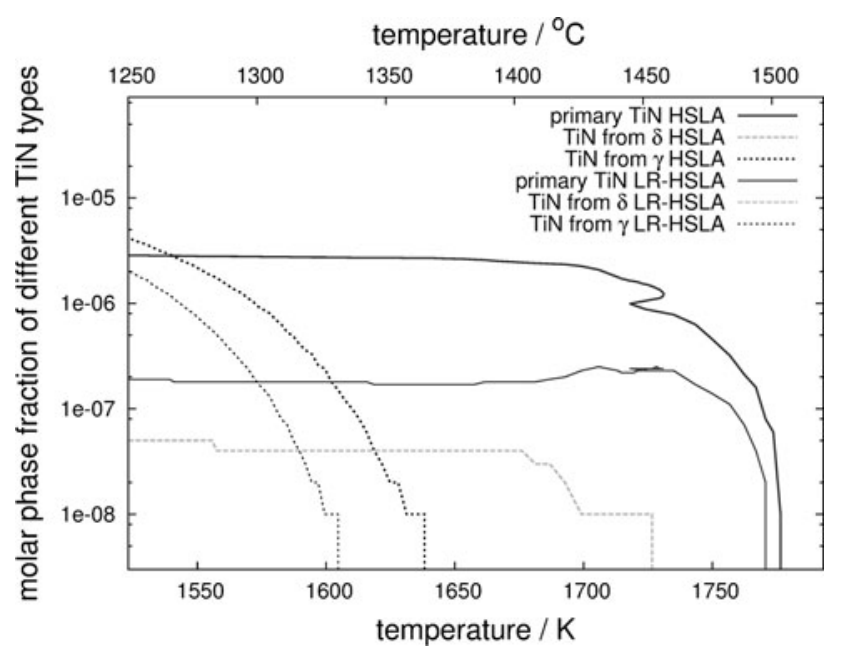

Fig. 8-Logarithmic plot of the carbonitride phase fraction vs temperature down to $1523 \mathrm{~K}\left(1250{ }^{\circ} \mathrm{C}\right)$ for a Ti composition of $0.003 \mathrm{wt}$ pct. Independent values are given for those particles which nucleated in the melt, in the $\delta$-ferrite, and the $\gamma$-austenite phase.

$\gamma$-austenite at much lower temperature. Furthermore, in the considered temperature range, the precipitates mainly consist of TiN. This means that, in accordance with empirical knowledge, ${ }^{[46]}$ the formation of particles which could affect the mechanical behavior at high temperatures strongly depends on the Ti and $\mathrm{N}$ content of the alloy.

Although TiN precipitation from the $\gamma$-austenite, which is shifted to a slightly higher temperature in HSLA compared to LR-HSLA, could also somehow affect crack propagation at temperatures below $1623 \mathrm{~K}$ $\left(1350{ }^{\circ} \mathrm{C}\right)$, the focus in this study is on those precipitates which form in the interdendritic liquid. For this purpose, a conventional simulation with a moving frame and $2000 \times 5000$ grid points was performed, which takes into account a Ti content of $0.003 \mathrm{wt}$ pct and nucleation of TiN in the melt. Figure 9 demonstrates where this type of TiN precipitation is taking place. Shown is the Ti distribution for a small section of the simulation domain at $t=0.7$ seconds. A further magnified subsection in Figure 9 reveals that TiN is forming at low temperatures just before solidification is completed. It should be quite reasonable and straightforward to assume that during this eutectic reaction, which is taking place in the thin channels of remaining liquid, the neighboring dendrites are fused together, i.e., coalescence is triggered. If this is the case, TiN precipitation from the melt could increase the coalescence temperature and thus reduce the hot cracking risk. And, as has been shown in Figure 8, TiN precipitation depends strongly on the $\mathrm{N}$ content of the alloy and thus is expected to be different in HSLA and LR-HSLA.

In the following part, it shall be assumed that the coalescence temperature is determined by the temperature where TiN starts forming, if this happens at a fraction of solid below 0.99. Otherwise, the default criterion $f_{\mathrm{S}}=0.99$ is used for determining the coalescence temperature $T_{\mathrm{c}}$. The TiN onset formation temperature and the corresponding value of $f_{\mathrm{S}}$ for LRHSLA and HSLA are evaluated in Figures 10 and 11, 


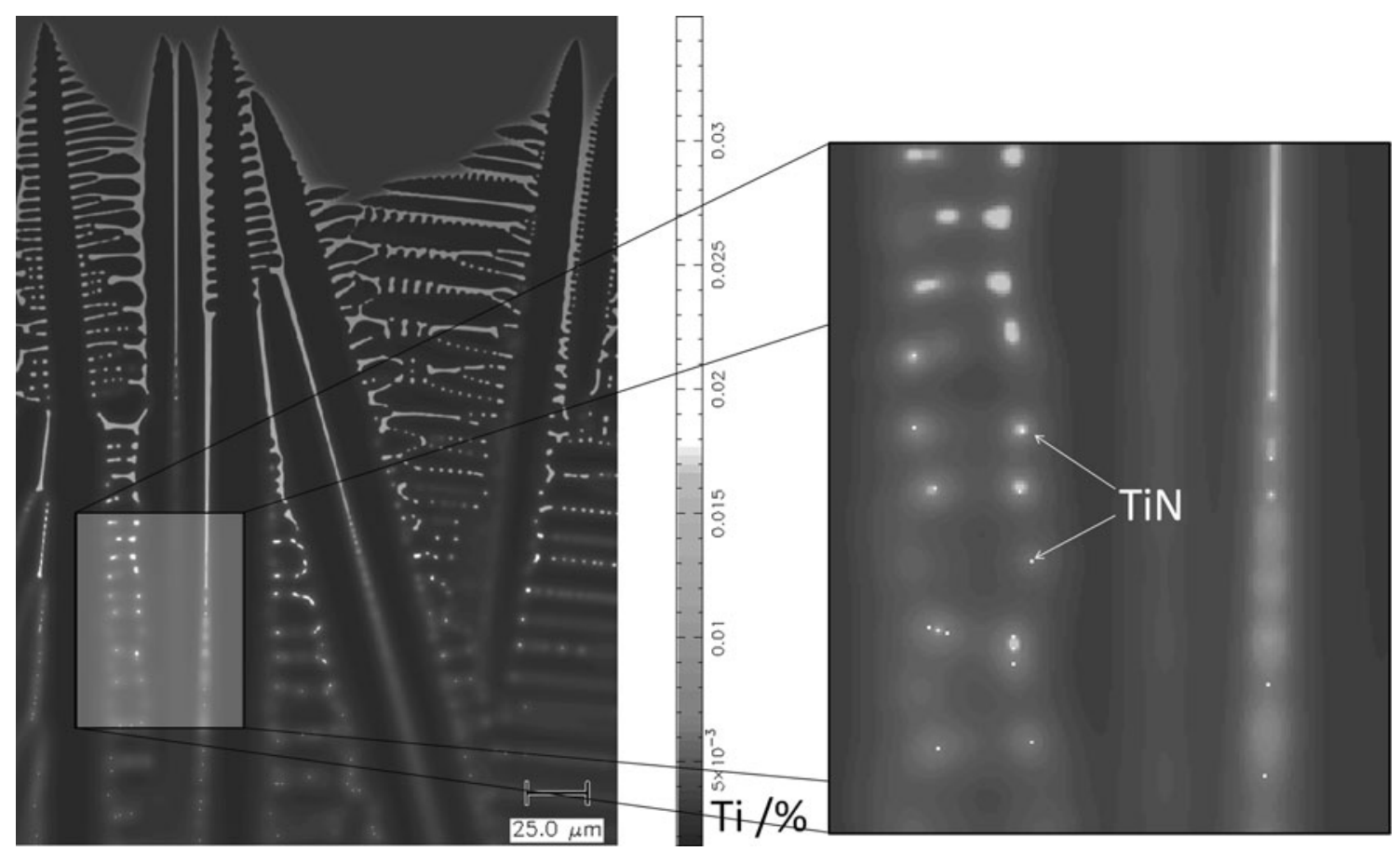

Fig. 9-Concentration distribution of Ti in HSLA $+0.003 \mathrm{wt}$ pct Ti after $0.7 \mathrm{~s}$ for a small section of the simulation domain, showing interdendritic TiN precipitation.

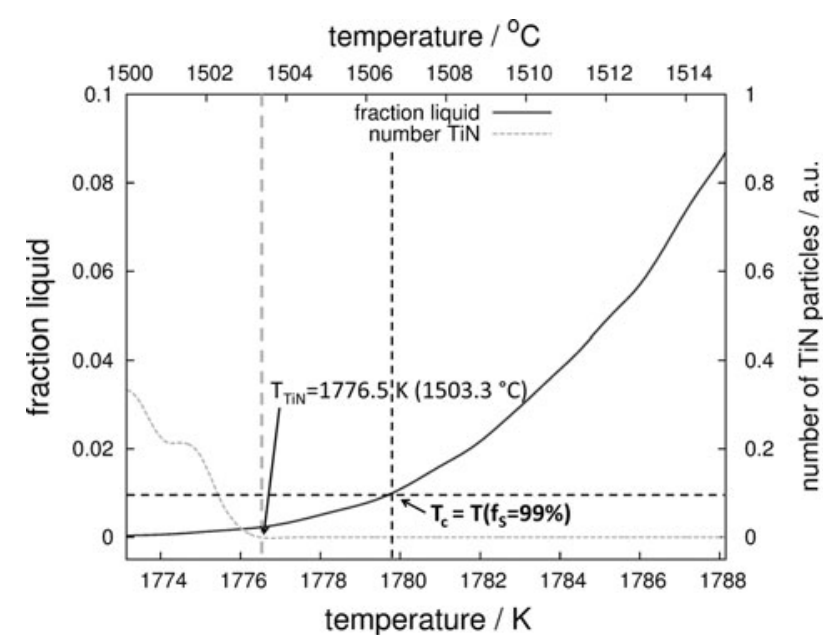

Fig. 10-Number density of TiN precipitates and fraction liquid plotted with temperature for LR-HSLA +0.003 pct Ti.

where a dimensionless number density of the TiN precipitations is plotted together with the fraction liquid against temperature. As can be seen, for HSLA, the TiN onset formation temperature lies nearly $2 \mathrm{~K}$ above the default coalescence temperature for $f_{\mathrm{S}}=0.99$, and a strong effect of TiN precipitation on hot cracking could be expected. On the other hand, for LR-HSLA, TiN forms well below the default coalescence temperature, and TiN precipitation should not alter the hot cracking behavior.

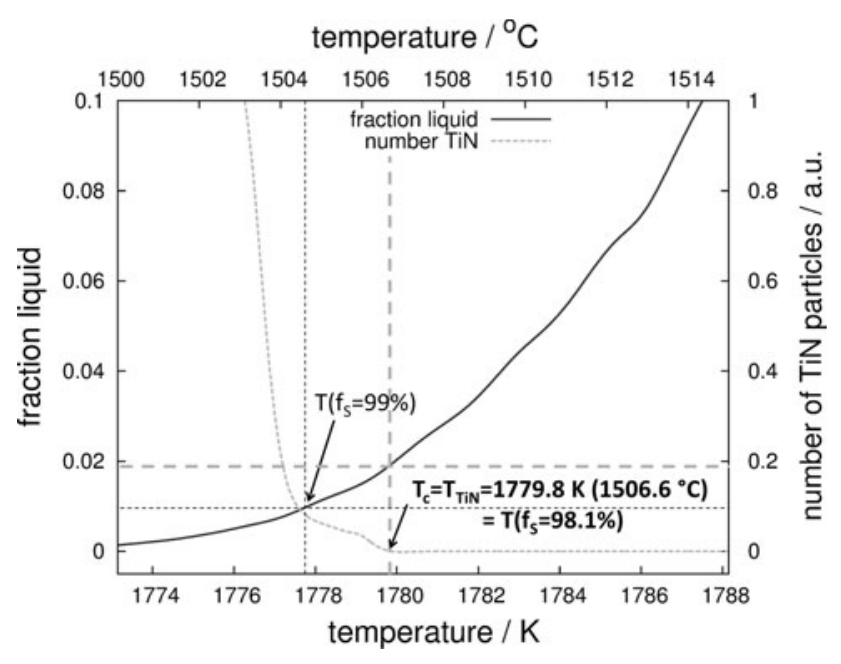

Fig. 11-Number density of TiN precipitates and fraction liquid plotted with temperature for HSLA +0.003 pet Ti.

Finally, Figure 12 shows the resulting prediction of hot cracking using the RDG criterion, if we take the corrected coalescence temperature for HSLA into account. Now, compared to Figure 7, the critical strain rate $\dot{\varepsilon}_{\text {crit }}$ and the critical strain $\varepsilon_{\text {crit }}$ are for HSLA more than a factor of 10 higher, which is in very good agreement with the breakout behavior observed during production. The criteria for coalescence, the corresponding coalescence temperature, and the resulting critical strain rate $\dot{\varepsilon}_{\text {crit }}$ and critical strain $\varepsilon_{\text {crit }}$ for the 


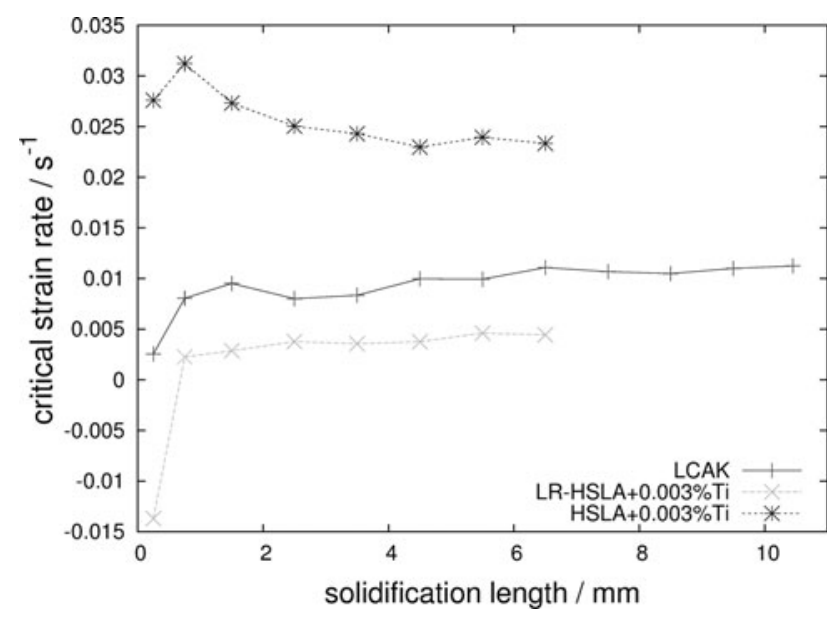

Fig. 12- Critical strain rate according to the RDG criterion including the effect of TiN precipitation.

Table V. Critical Fraction Solid for Coalescence, Corresponding Coalescence Temperature $T_{\mathrm{c}}$, Critical Strain Rate $\dot{\varepsilon}_{\text {crit }}$, and Critical Strain $\varepsilon_{\text {crit }}$ for HLSA and LR-HSLA With and Without Ti

\begin{tabular}{|c|c|c|c|c|}
\hline Steel Grade & $f_{\mathrm{S}}$ & $T_{\mathrm{c}}\left[\mathrm{K}\left({ }^{\circ} \mathrm{C}\right)\right]$ & $\begin{array}{c}\dot{\varepsilon}_{\text {crit }} \\
\left(\text { Pct s }^{-1}\right)\end{array}$ & $\begin{array}{l}\varepsilon_{\text {crit }} \\
(\mathrm{Pct})\end{array}$ \\
\hline LR-HSLA & 0.99 & $1779.57(1506.42)$ & 0.2855 & 0.02513 \\
\hline $\begin{array}{l}\text { LR-HSLA }+0.003 \\
\text { Pct Ti }\end{array}$ & 0.99 & $1779.57(1506.42)$ & 0.2855 & 0.02513 \\
\hline HSLA & 0.99 & $1777.89(1504.74)$ & 0.2273 & 0.02205 \\
\hline $\begin{array}{l}\text { HSLA }+0.003 \\
\text { Pct Ti }\end{array}$ & 0.981 & $1779.75(1506.60)$ & 2.733 & 0.2651 \\
\hline
\end{tabular}

reference location $x=1$ to $2 \mathrm{~mm}$ are summarized in Table V.

\section{SUMMARY}

In this paper, phase-field simulation has been applied to study microstructure formation during the formation of the first solid shell in an industrial continuous casting process of steel. An efficient phase-field model coupled to thermodynamic databases incorporates a 1D macroscopic temperature solver and uses an advanced approach to insure consistency between the microstructure scale and the temperature field. Simulation of the complete solid shell which forms inside the continuous casting mold up to a thickness of $10 \mathrm{~mm}$ has been performed for a 2D moving slice of the slab.

The study is motivated by the problem of breakouts of steel slabs during industrial continuous casting. Different breakout risks were observed for different steels which were not fully understood. Three industrial steel grades, one low-carbon (LCAK) steel and two high-strength low-alloyed (HSLA) steels, had been selected for this study with the aim to better understand their specific hot cracking behavior.

Consistent quantitative microstructure parameters were found for the three quite similar steel grades. The secondary arm spacing $\lambda_{2}$ and the fraction liquidtemperature curves were found to change in parallel with an increasing content of alloying elements. With these parameters, a quantitative evaluation of the RDG criterion for hot cracking could be performed for all three alloys and across the whole thickness of the shell. It was shown that considering only the solutal effects of the alloying elements, the different breakout risks could only partially be explained. In particular, the strongly reduced breakout risk, which was observed for an HSLA grade with increased $\mathrm{V}$ and $\mathrm{N}$ content, is in contradiction of the modeling results.

In order to better understand the special behavior of this HSLA grade, the potential for precipitation of TiN was evaluated by performing phase-field simulations including the additional element $\mathrm{Ti}$. It could be shown that TiN can form already during the latest stage of solidification, even if $\mathrm{Ti}$ is not specified in the alloy grades and only very low amounts of this element are present. With the hypothesis that TiN particles can trigger the coalescence of dendrite trunks, it is possible to understand why, for a given Ti content, an increased $\mathrm{N}$ content can help to reduce the risk of hot cracking. This effect of TiN precipitation could be quantified by assuming an increased coalescence temperature in case the TiN start temperature lies above the default coalescence temperature at $f_{\mathrm{S}}=0.99$, and full agreement between the observed breakout behavior and the modeling results was achieved.

The results of this study indicate that a slight increase in the $\mathrm{Ti}$ and $\mathrm{N}$ content of LR-HLSA steels could substantially reduce the risk of breakouts during continuous casting. The presented numerical findings should be verified by further experimental investigations on the presence of TiN in the solidification microstructure $^{[47]}$ and on its effects on the coalescence temperature as well as by a more detailed analysis of the industrial breakout data. ${ }^{[32]}$

\section{REFERENCES}

1. M. Rappaz, J.-M. Drezet, and M. Gremaud: Metall. Mater. Trans. A, 1999, vol. 30A, pp. 449-55.

2. J.M. Drezet, M. Gremaud, R. Graf, and M. Gäumann: in Proceedings of 5th European Cont. Casting Conference, Birmingham, 2003, pp. 755-63.

3. P.-D. Grasso, J.-M. Drezet, and M. Rappaz: J. Miner. Met. Mater. Soc. (JOM), 2002, http://www.tms.org/pubs/journals/JOM/ jom.htm.

4. D.G. Eskin, Suyitno, and L. Katgerman: Prog. Mater. Sci., 2004, vol. 49 , pp. 629-711.

5. T.W. Clyne and G.J. Davies: Br. Foundryman, 1981, vol. 4, pp. 6573.

6. D. Raabe: Annu. Rev. Mater. Res., 2002, vol. 32, pp. 53-76.

7. H. Yang, C. Wu, H. Li, and X.G. Fan: Sci. China Technol. Sci., 2011 , vol. 54 , pp. $2107-18$.

8. Ch.-A. Gandin and M. Rappaz: Acta Metall. Mater., 1994, vol. 42 , pp. 2233-46. 
9. A. Wheeler, W.J. Boettinger, and G.B. Mc Fadden: Phys. Rev. E, 1993, vol. 47, pp. 1893-1909.

10. A. Karma, Y.H. Lee, and M. Plapp: Phys. Rev. E, 2000, vol. E61, pp. 3996-4006.

11. R. Kobayashi: Physica D, 1993, vol. 63, pp. 410-23.

12. S.G. Kim, W.T. Kim, and T. Suzuki: Phys. Rev. E, 1999, vol. 60, pp. 7186-97.

13. I. Steinbach, F. Pezzolla, B. Nestler, M. Seeßelberg, R. Prieler, G.J. Schmitz, and J.L.L. Rezende: Physica D, 1996, vol. 94, pp. $135-47$.

14. J. Tiaden, B. Nestler, H.J. Diepers, and I. Steinbach: Physica D, 1998 , vol. 115 , pp. $73-86$.

15. I. Steinbach and F. Pezolla: Physica D, 1999, vol. 134, pp. 385-93.

16. B. Nestler and A.A. Wheeler: Physica D, 2000, vol. 138, pp. 114 33.

17. N Saunders and A Miodownik: CALPHAD Calculation of Phase Diagrams: A Comprehensive Guide, Elsevier, Amsterdam, 1998.

18. Themo-Calc Software: http://www.thermocalc.se. Accessed 14 Jan 2013.

19. http://www.micress.de. Accessed 14 Jan 2013.

20. www.access-technology.de. Accessed 14 Jan 2013.

21. B. Böttger, U. Grafe, D. Ma, and S.G. Fries: Mater. Sci. Technol., 2000, vol. 16, pp. 1425-28.

22. J. Eiken, B. Böttger, and I. Steinbach: Phys. Rev. E, 2006, vol. 73, p. 066122 .

23. J. Rösler, M. Götting, D. Del Genovese, B. Böttger, R. Kopp, M. Wolske, F. Schubert, H.J. Penkalla, T. Seliga, A. Thoma, A. Scholz, and C. Berger: Adv. Eng. Mater., 2003, vol. 5(7), pp. 469-83.

24. N. Warnken, D. Ma, M. Mathes, and I. Steinbach: Mater. Sci. Eng. A, 2005, vols. 413-414, pp. 267-71.

25. B. Böttger, J. Eiken, and I. Steinbach: Acta Mater., 2006, vol. 54 , pp. 2697-2704.

26. B. Böttger, J. Eiken, M. Ohno, G. Klaus, M. Fehlbier, R. SchmidFetzer, I. Steinbach, and A. Bührig-Polaczek: Adv. Eng. Mater., 2006, vol. 8 (4), pp. 241-47.

27. I. Steinbach and M. Apel: Acta Mater., 2007, vol. 55, pp. 4817-22.
28. K. Nakajima, M. Apel, and I. Steinbach: Acta Mater., 2006, vol. 54, pp. 3665-72.

29. B. Böttger, M. Apel, J. Eiken, P. Schaffnit, and I. Steinbach: Steel Res. Int., 2008, vol. 79 (8), pp. 608-16.

30. D. Senk, S. Stratemeier, B. Böttger, E. Subasic, K. Göhler, and I. Steinbach: Adv. Eng. Mater., 2010, vol. 12 (4), pp. 94-100.

31. B. Böttger, S. Stratemeier, E. Subasic, K. Göhler, I. Steinbach, and D. Senk: Adv. Eng. Mater., 2010, vol. 12 (4), pp. 101-09.

32. Internal Statistical Analysis 2007-2008, Corus, IJmuiden, The Netherlands.

33. B. Böttger, J. Eiken, and M. Apel: J. Comput. Phys., 2009, vol. 228 , pp. 6784-95.

34. B. Santillana, L.C. Hibbeler, B.G. Thomas, A.A. Kamperman, and W. van der Knoop: ISIJ Int., 2011, vol. 48 (10), pp. 1380-88.

35. http://www.efunda.com. Accessed 14 Jan 2013.

36. A. Karma and W.J. Rappel: Phys. Rev. E, 1997, vol. 57, pp. 4323-49.

37. R. Almgren: J. Appl. Math., 1999, vol. 59, pp. 2086-2107.

38. S.G. Kim: Acta Mater., 2007, vol. 55, pp. 4391-99.

39. A. Choudhury and B. Nestler: Phys. Rev. E, 2012, vol. 85, p. 021602 .

40. J. Eiken: Mater. Sci. Eng., 2012, vol. 33, p. 012105.

41. I. Maxwell and A. Hellawell: Acta Metall., 1975, vol. 23, pp. 229 37.

42. T.E. Quested and A.L. Greer: Acta Mater., 2004, vol. 52, pp. 3859-68.

43. A.L. Greer, P.S. Cooper, M.W. Meredith, W. Schneider, P. Schumacher, J.A. Spittle, and A. Tronche: Adv. Eng. Mater., 2003, vol. 5, pp. 81-91.

44. B. Böttger, M. Apel, B. Santillana, and D.G. Eskin: Mater. Sci. Eng., 2012, vol. 33, p. 012107.

45. B. Santillana, B.G. Thomas, G. Botman, and E. Dekker: in Conference Contribution to the 7th ECCC, held in Düsseldorf, Germany on 27 June-1 July 2011.

46. R. Lagneborg, T. Siwecki, S. Zajac, and B. Hutchinson: Scand. J. Metall., 1999, vol. 28 (5), pp. 186-241.

47. F. Ma, G. Wen, P. Tang, G. Xu, F. Mei, and W. Wang: Metall. Mater. Trans. B, 2011, vol. 42B, pp. 81-86. 